\title{
Danos causados por diferentes níveis de desfolha artificial para simulação do ataque de formigas cortadeiras em Pinus taeda e Eucalyptus grandis
}

\author{
Wilson Reis Filho', Franciele dos Santos ${ }^{2}$, Priscila Strapasson ${ }^{3}$, Mariane Aparecida Nickele ${ }^{3}$
}

\begin{abstract}
${ }_{1}^{1}$ Pesquisador da Epagri/Embrapa Florestas, Estrada da Ribeira, Km 111, CP 319, CEP 83411-000, Colombo, PR, Brasil, wilson@cnpf.embrapa.br; 2Faculdades Integradas Espírita, Rua Tobias de Macedo Júnior, 246, Santo Inácio, CEP 82010-340, Curitiba, PR, Brasil, francielesantos.bio@hotmail.com; 3Universidade Federal do Paraná, Departamento de Zoologia, CP 19020, CEP 81531-980, Curitiba, PR, Brasil, pristrapasson@hotmail.com; nickele.mariane@gmail.com
\end{abstract}

\begin{abstract}
Resumo - A desfolha artificial permite mensurar a intensidade do dano devido à desfolha causada por insetos. No presente estudo, buscou-se avaliar os danos causados por formigas cortadeiras em plantios de Pinus taeda e Eucalyptus grandis com 30 dias de idade. Foi estabelecida uma classificação baseada em níveis de desfolha semelhantes aos causados por formigas cortadeiras. Para P. taeda, os níveis foram: N1: 50\%, N2: 75\%, N3: 100\% e N4: $100 \%$ de desfolha, incluindo o corte do meristema apical. Para E. grandis, os níveis foram N1: 50\%, N2: $75 \%$ e N3: 100\% de desfolha, incluindo o corte do meristema apical. Após um ano, as mudas de P. taeda tiveram perdas em altura e diâmetro nos níveis de N2 a N4. Mudas de P. taeda desfolhadas no nível N4 apresentaram perdas de 37,0\% em altura e 45,4\% em diâmetro. As mudas de E. grandis apresentaram perdas aos três meses de idade, sendo estas proporcionais à intensidade de desfolha. Após um ano, verificaram-se perdas de 13,3\% em altura e $20 \%$ em diâmetro, nas plantas de $P$. taeda que tiveram $100 \%$ de desfolha. Plantas de $P$. taeda foram mais prejudicadas pela simulação do ataque de formigas cortadeiras do que as de E. grandis.
\end{abstract}

Termos para indexação: Níveis de dano, plantios florestais, pragas florestais.

\section{Damage caused by different levels of artificial defoliation, simulating the leaf-cutting ants attack on young plantations of Pinus taeda and Eucalyptus grandis}

\begin{abstract}
The artificial defoliation allows to measure the defoliation intensity caused by insects. The objectives of this work were to evaluate the damages caused by leaf-cutting ants in young plantations of Pinus taeda and Eucalyptus grandis using different levels of artificial defoliation. A classification was established according to defoliation levels that were caused by leaf-cutting ants in P. taeda: level 1:50\%, level 2: 75\%, level 3:100\% and level 4: 100\%, including the cut of the apical meristem. And in E. grandis: level 1: 50\% of defoliation; level 2: $75 \%$ and level 3: $100 \%$. After one year, the $P$. taeda seedlings had losses in diameter and height for defoliation level above $75 \%$. Seedlings severely defoliated (level 4), had losses of $37.0 \%$ in height and $45.4 \%$ in diameter. The E. grandis seedlings had losses since three months old and the reductions were proportional to the defoliation intensity. After one year, the losses of $13.3 \%$ in height and $20 \%$ in diameter were verified in plants with $100 \%$ of defoliation. P. taeda plants are more damaged by leaf-cutting attack.
\end{abstract}

Index terms: Damage levels, forest plantations, forest pests.

\section{Introdução}

Características como rápido crescimento e boa adaptação às condições edafoclimáticas fizeram das espécies de Eucalyptus e Pinus as mais utilizadas em programas de reflorestamento do Brasil. Estas espécies, inicialmente, foram pouco atacadas por pragas quando introduzidas, principalmente por estes insetos ainda não estarem adaptados às mesmas (Ribeiro \& Mendonça,
2004). Atualmente, as formigas cortadeiras são apontadas como as pragas mais importantes nesses reflorestamentos, em razão dos prejuízos que causam e de sua ampla região de ocorrência (Antunes \& Della Lucia, 1999).

Em mudas de Pinus taeda, o ataque de formigas cortadeiras tem início na parte basal das plantas, podendo chegar ao ápice, e até cortar o meristema apical (Nickele, 2008). Já em mudas de Eucalyptus grandis, o ataque 
começa na parte superior das plantas, progredindo em direção à base, caracterizando-se pelo corte das folhas e ponteiros mais tenros (Anjos et al., 1998).

As perdas causadas por formigas cortadeiras variam de acordo com a idade da planta e a intensidade do ataque. Em casos de ataques intensos e constantes, as perdas podem chegar a $100 \%$ da produção. Quando o ataque ocorre na fase inicial do plantio, as perdas podem ser irreversíveis (Anjos et al., 1993). Além disso, os prejuízos causados não se restringem apenas à diminuição de produção, mas também da resistência das plantas, deixando-as mais suscetíveis ao ataque de outros insetos e de doenças (Ferreira, 1989), além do alto custo das atividades de monitoramento e combate à praga (Zanuncio et al., 1996). Vilela (1986) observou que as formigas cortadeiras representam $75 \%$ dos custos e do tempo gasto no controle de pragas florestais. Alípio (1989) relatou que elas representam $30 \%$ dos gastos com a floresta até o terceiro ciclo, o que, segundo Rezende et al. (1983), corresponde a 7,4\% do preço da madeira em pé. Estimativas de danos provocados por formigas cortadeiras são relativamente complexas, em razão da influência de inúmeras variáveis, como a espécie de formiga, número e tamanho de formigueiros, disponibilidade de outros materiais vegetais, entre outras, cujo conhecimento se torna indispensável nas ações de manejo e controle. Soma-se a isso o fato de existirem poucos estudos relacionados à bioecologia destas espécies, os quais fornecem subsídios para a quantificação desses prejuízos (Antunes \& Della Lucia, 1999).

A desfolha artificial pode ser um instrumento valioso, permitindo mensurar a intensidade da desfolha causada por insetos. A redução no incremento de árvores desfolhadas pode ser determinada em comparação com árvores livres de danos (testemunhas), cultivadas nas mesmas condições (Kulman, 1971).

Nesse sentido, este trabalho teve por objetivo avaliar as perdas causadas pela simulação do ataque de formigas cortadeiras no crescimento em altura e diâmetro de plantas de E. grandis e $P$. taeda, nos estágios iniciais de desenvolvimento, por meio dos diferentes níveis de desfolha artificial.

\section{Material e métodos}

Os experimentos foram realizados no Município de Telêmaco Borba (24¹8'59'S/050³9'08'W), Paraná, entre dezembro de 2006 e novembro de 2007.
Com base em avaliações preliminares nas áreas de estudo, estabeleceu-se uma classificação para os níveis de desfolha causados por formigas cortadeiras. Para as mudas de E. grandis, os níveis de desfolha foram classificados em: N0: 0\%, N1: 50\%, N2: $75 \%$ e N3: $100 \%$ de desfolha. Já nas mudas de P. taeda, além do corte parcial, pode ocorrer o corte total das acículas, com ou sem o corte do meristema apical (Nickele, 2008). Por isso, os níveis de desfolha foram classificados em: N0: $0 \%$, N1: $50 \%$, N2: $75 \%$, N3: $100 \%$ e N4: $100 \%$ de desfolha, incluindo o corte do meristema apical.

Em mudas de pínus, assim como nas de eucaliptos, a desfolha artificial foi realizada com auxílio de tesouras de poda em 20 plantas para cada nível de desfolha, 30 dias após o plantio das mudas, desfolhando-se da parte basal para a parte apical das plantas.

As plantas foram identificadas e numeradas de acordo com o nível de desfolha realizado, utilizando-se estacas de madeira fixadas ao lado da planta. Foram utilizadas cinco linhas de plantio. As plantas utilizadas distanciavam entre si, no máximo cinco plantas dentro da mesma linha, preferindo-se as de maior volume de copa.

Realizou-se a medição da altura das plantas aos três e seis meses de idade do plantio. Quando o plantio de E. grandis completou um ano de idade, em dezembro de 2007, foram medidos a altura, utilizando-se uma régua telescópica, e o DAP (diâmetro à altura do peito) das plantas, com o auxílio de um paquímetro digital. Nas mudas de P. taeda, também com um ano de idade, mediram-se a altura e o diâmetro do caule das plantas a $5 \mathrm{~cm}$ do solo.

Os dados foram submetidos à análise de regressão para os percentuais de desfolha, excluindo o tratamento que envolveu corte do meristema apical, e análise gráfica com barra de intervalos de confiança ao nível de 5\%.

\section{Resultados e discussão}

Até os três meses de idade, a altura das plantas de $P$. taeda não foi afetada por nenhum dos níveis de desfolha. Aos seis meses, as plantas submetidas ao tratamento N2 diferiram significativamente em altura, diferença que desapareceu aos 12 meses, indicando uma recuperação das plantas e sua tolerância ao corte de até $75 \%$ das acículas, quando com um mês de idade (Figura 1). Resultados similares foram encontrados por Nickele (2008), utilizando a desfolha artificial para determinar os danos causados por formigas cortadeiras em P. taeda, 
verificando que, aos seis meses de idade, somente a desfolha de $100 \%$, incluindo o corte do meristema apical, prejudicou a altura das plantas. Esses resultados mostram que a altura das plantas de $P$. taeda pode ser pouco afetada pela desfolha parcial, mesmo quando altamente suscetíveis.

Figura 1. Altura média \pm intervalo de confiança $(p<0,05)$ de

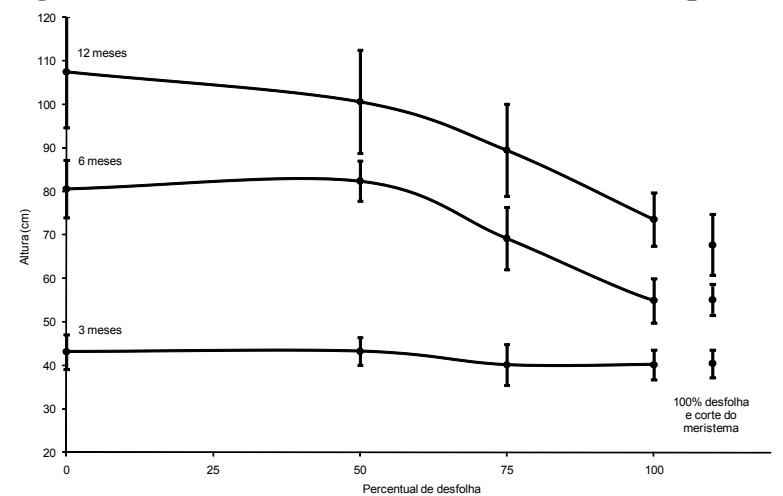

plantas de Pinus taeda que sofreram desfolha artificial aos 30 dias de idade do plantio em diferentes níveis. Telêmaco Borba, 2006-2007.

Quanto ao diâmetro das plantas de P. taeda, as plantas desfolhadas em $50 \%$ não diferiram significativamente da testemunha (Figura 2). Observou-se que as plantas de $P$. taeda foram mais afetadas no diâmetro do que na altura. Enquanto houve perda de $37 \%$ na altura das plantas desfolhadas ao nível de $100 \%$, incluindo o corte do meristema apical, as perdas em diâmetro foram de $45 \%$ (Tabela 1). Esse fato foi observado também por Ribeiro \& Woessner (1980), estudando a desfolha artificial em Gmelina arborea e Pinus caribaea var. hondurensis, indicando a necessidade de novos estudos visando verificar a influência da desfolha na produção de madeira.

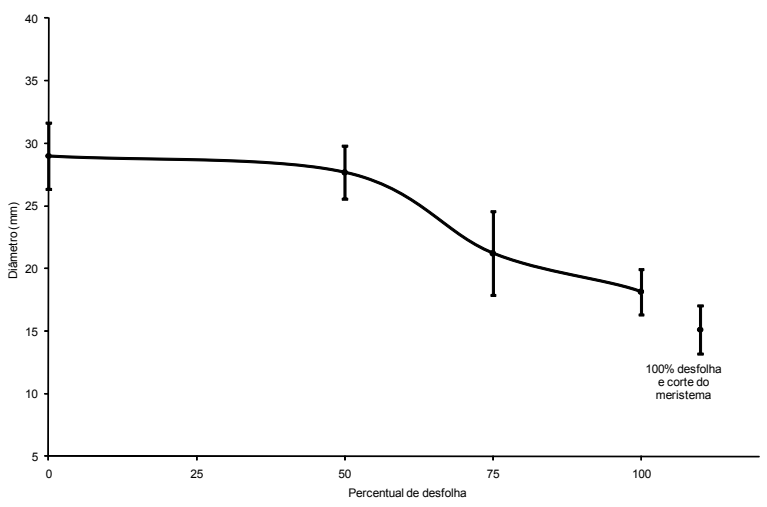

Figura 2. Diâmetro médio \pm intervalo de confiança $(p<0,05)$ de plantas de Pinus taeda que sofreram desfolha artificial aos 30 dias de idade do plantio em diferentes níveis. Telêmaco Borba, 2006-2007.

Tabela 1. Porcentagem de sobrevivência e perdas em altura e diâmetro de plantas de Pinus taeda que sofreram desfolha artificial, aos 30 dias de idade do plantio, em relação às testemunhas. Telêmaco Borba, 2006-2007.

\begin{tabular}{|c|c|c|c|c|}
\hline & Níveis $^{(1)}$ & $\begin{array}{c}\text { Sobrevivência } \\
(\%)\end{array}$ & $\begin{array}{c}\text { Perdas } \\
\text { em Altura } \\
(\%) \\
\end{array}$ & $\begin{array}{c}\text { Perdas em } \\
\text { Diâmetro } \\
(\%)\end{array}$ \\
\hline \multirow{5}{*}{3 meses } & No & 100 & - & - \\
\hline & N1 & 100 & $-0,2$ & - \\
\hline & $\mathrm{N} 2$ & 100 & 7,1 & - \\
\hline & N3 & 90 & 6,9 & - \\
\hline & N4 & 100 & 6,5 & - \\
\hline \multirow{5}{*}{6 meses } & No & 100 & - & - \\
\hline & N1 & 100 & $-2,2$ & - \\
\hline & N2 & 100 & 14,1 & - \\
\hline & N3 & 90 & 31,9 & - \\
\hline & N4 & 100 & 33,1 & - \\
\hline \multirow{5}{*}{12 meses } & No & 100 & - & - \\
\hline & N1 & 100 & 6,4 & 4,4 \\
\hline & $\mathrm{N} 2$ & 100 & 16,8 & 26,8 \\
\hline & N3 & 75 & 31,6 & 37,4 \\
\hline & N4 & 85 & 37,0 & 45,4 \\
\hline
\end{tabular}

(1) N0: testemunha; N1: 50\% de desfolha; N2: 75\% de desfolha; N3: 100\% de desfolha; N4: 100\% de desfolha mais o corte do meristema apical. 
As equações de regressão obtidas para os tratamentos em plantas de $P$. taeda mostraram que houve tendência linear decrescente aos três meses (Altura $=0,0344 x$ $\left.+43,603 ; \mathrm{R}^{2}=0,69\right)$ e tendência na forma quadrática decrescente aos seis (Altura $=-0,0054 x+0,2747 x$ $+80,32 ; \mathrm{R}^{2}=0,98$ ) e 12 meses (Altura $=-0,004 x^{2}+$ $\left.0,061 x+107,56 ; \mathrm{R}^{2}=0,99\right)$ para a variável altura. Houve tendência na forma quadrática decrescente para a variável diâmetro aos 12 meses (Diâmetro $=-0,0012 x^{2}$ $\left.+0,0079 x+29,193 ; \mathrm{R}^{2}=0,97\right)$.

A mortalidade de plantas de $P$. taeda só ocorreu quando submetidas ao tratamento $\mathrm{N} 3$, já aos três meses de idade, quando a mortalidade atingiu $10 \%$. Aos 12 meses, atingiu $25 \%$ das plantas, mesmo sem o corte do meristema apical (Tabela 1).

Em mudas de E. grandis, ao contrário do que ocorreu em $P$. taeda, as plantas já apresentavam perdas na altura aos três meses. Plantas com $50 \%$ e $75 \%$ de desfolha sofreram reduções significativas na altura (Figura 3). Aos seis meses após o plantio, no entanto, foi observada a recuperação das plantas submetidas a N2, observandose perda de crescimento naquelas desfolhadas em 100\%. Aos 12 meses, apenas as plantas submetidas a N1 não apresentaram diferença significativa na altura. Quanto ao diâmetro das plantas de $E$. grandis, assim como aconteceu com a altura, as plantas desfolhadas em $50 \%$ não diferiram significativamente da testemunha (Figura 4).

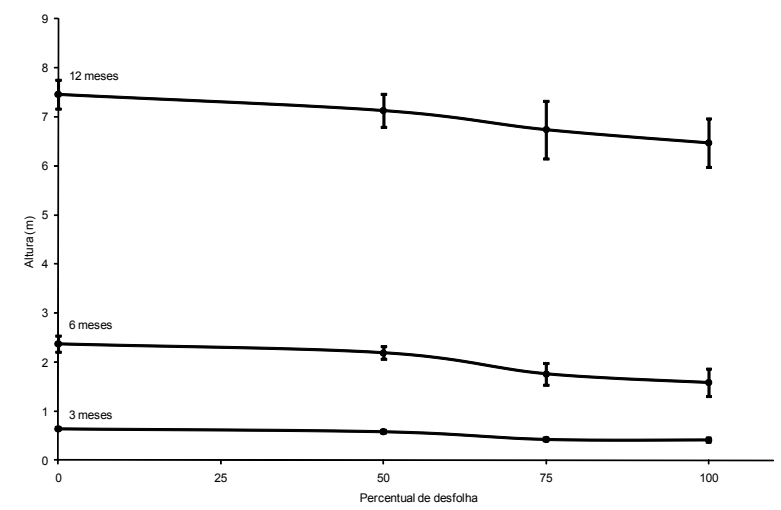

Figura 3. Altura média \pm intervalo de confiança $(\mathrm{p}<0,05)$ de plantas de Eucalyptus grandis que sofreram desfolha artificial aos 30 dias de idade do plantio em diferentes níveis. Telêmaco Borba, 2006-2007.

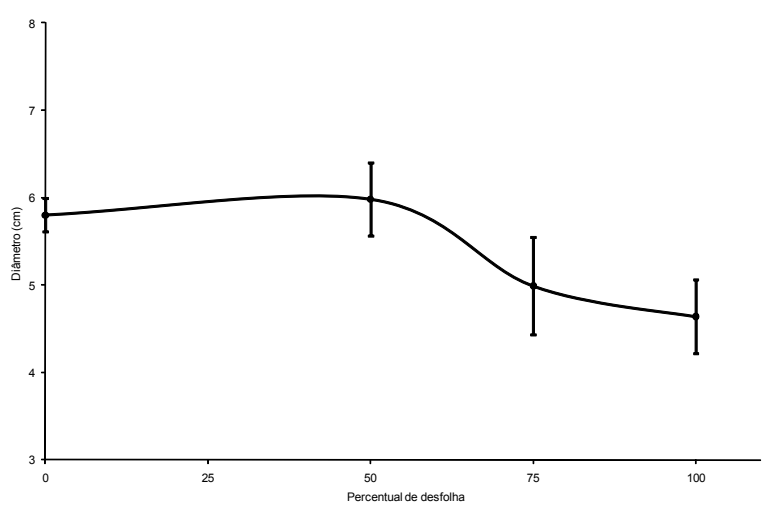

Figura 4. Diâmetro médio \pm intervalo de confiança $(p<0,05)$ de plantas de Eucalyptus grandis que sofreram desfolha artificial aos 30 dias de idade do plantio em diferentes níveis. Telêmaco Borba, 2006-2007.

As equações de regressão obtidas para os tratamentos em plantas de E. grandis mostraram que para a variável altura houve tendência linear decrescente aos três meses (Altura $=-0,0025 x+0,6546 ; \mathrm{R}^{2}=0,87$ ) e tendência na forma quadrática decrescente aos seis (Altura $=$ $\left.-0,0000005 x^{2}+0,0024 x+2,383 ; \mathrm{R}^{2}=0,95\right)$ e 12 meses (Altura $\left.=-0,000005 x^{2}+0,0061 x+7,4674 ; \mathrm{R}^{2}=0,98\right)$. Houve tendência na forma quadrática decrescente aos 12 meses (Diâmetro $=-0,0002 x^{2}+0,0099 x+5,8371$; $\left.\mathrm{R}^{2}=0,88\right)$ para a variável diâmetro.

O tratamento N1 não causou mortalidade de plantas de $E$. grandis, sendo que o número de plantas mortas aumentou com a intensidade da desfolha (Tabela 2). Esses resultados complementam os encontrados por Lewis \& Norton (1973), que afirmam serem maiores os danos causados por formigas cortadeiras em árvores de Eucalyptus de um a três anos de idade e que um desfolhamento total retarda o crescimento da árvore, e que dois consecutivos podem acarretar a sua morte. Já Mendes Filho (1979) verificaram que pode ocorrer morte de árvores de eucaliptos se estas forem totalmente desfolhadas três vezes consecutivas. 
Tabela 2. Porcentagem de sobrevivência, altura e diâmetro de plantas de Eucalyptus grandis que sofreram desfolha artificial aos 30 dias de idade do plantio, em diferentes níveis, em relação às testemunhas. Telêmaco Borba, 2006-2007.

\begin{tabular}{|c|c|c|c|c|}
\hline & Níveis $^{(1)}$ & $\begin{array}{c}\text { Sobrevivência } \\
(\%)\end{array}$ & $\begin{array}{c}\text { Perdas } \\
\text { em Altura } \\
(\%)\end{array}$ & $\begin{array}{c}\text { Perdas em } \\
\text { Diâmetro } \\
(\%)\end{array}$ \\
\hline \multirow{4}{*}{3 meses } & No & 100 & - & - \\
\hline & N1 & 100 & 9,4 & - \\
\hline & N2 & 95 & 34,4 & - \\
\hline & N3 & 90 & 35,9 & - \\
\hline \multirow{4}{*}{6 meses } & No & 100 & - & - \\
\hline & N1 & 100 & 7,6 & - \\
\hline & $\mathrm{N} 2$ & 95 & 25,7 & - \\
\hline & N3 & 90 & 33,3 & - \\
\hline \multirow{4}{*}{12 meses } & No & 100 & - & \\
\hline & N1 & 100 & 4,4 & $-3,1$ \\
\hline & N2 & 95 & 9,6 & 13,9 \\
\hline & N3 & 90 & 13,3 & 20,0 \\
\hline
\end{tabular}

${ }^{(1)}$ N0: testemunha; N1: $50 \%$ de desfolha; N2: $75 \%$ de desfolha; N3: $100 \%$ de desfolha.

Verificou-se a redução no crescimento em altura e no diâmetro das plantas de E. grandis em função da intensidade de desfolha. Aos 12 meses após a desfolha de $100 \%$ nas mudas de $E$. grandis, constataram-se perdas de $13,2 \%$ e $20 \%$ nos incrementos em altura e diâmetro, respectivamente (Tabela 2). Estes resultados concordam com Freitas \& Berti Filho (1994) e Martinez \& Wagner (1994,) que verificaram redução no crescimento das plantas com o aumento da intensidade da desfolha.

Embora sejam necessários novos estudos visando verificar possíveis perdas na produção de madeira decorrentes da desfolha para as duas espécies avaliadas, plantas de $P$. taeda com um mês toleram desfolha de até $75 \%$ das acículas, mas a desfolha total pode causar a morte de $25 \%$ das plantas. Já as plantas de E. grandis são mais sensíveis à desfolha nessa idade quanto à altura, com tolerância de até $50 \%$ de desfolha, ocorrendo mortalidade de $5 \%$ das plantas já aos três meses de idades. A mortalidade, no entanto, é mais expressiva em P. taeda (25\%) do que em E. grandis (10\%).

Esses resultados evidenciaram que há necessidade de continuidade dos estudos relacionados aos prejuízos que as formigas cortadeiras podem causar em P. taeda e em E. grandis, visando diminuir a utilização de formicidas químicos para o combate desses insetos.

\section{Conclusões}

A desfolha com intensidade de $50 \%$ em plantas de Pinus taeda e Eucalyptus grandis com um mês de idade não afeta o crescimento em altura nem o diâmetro.

A desfolha de até $75 \%$ em plantas de $P$. taeda, com um mês após o plantio não causa mortalidade, enquanto que em E. grandis causa a mortalidade de $5 \%$ das plantas.

A desfolha de $100 \%$ da planta e o corte do meristema apical, com um mês de idade do plantio, causa mais mortalidade em plantas de $P$. taeda (25\%) do que de $E$. grandis $(10 \%)$.

A desfolha afeta mais o diâmetro do que a altura das plantas de P. taeda e E. grandis.

\section{Agradecimentos}

À Klabin do Paraná, pelo apoio financeiro e por ceder as áreas para a condução dos estudos.

\section{Referências}

ALÍPIO, A. S. Controle de formigas cortadeiras. Normas técnicas da Pains Florestal. 1989. 8 p.

ANJOS, N.; DELLA-LUCIA, T. M. C.; MAYHÉ-NUNES, A. J. Guia prático sobre formigas cortadeiras em reflorestamentos. Ponte Nova: Editora Graff Cor, 1998. 100 p.

ANJOS, N.; MOREIRA, D. D; DELLA LUCIA, T. M. C. Manejo integrado de formigas em reflorestamentos. In: DELLA LUCIA, T. M. C. (Ed.). As formigas cortadeiras. Viçosa, 1993. p. 212-241.

ANTUNES, E. C.; DELLA LUCIA, T. M. C. Consumo foliar em Eucalyptus urophylla por Acromyrmex laticeps nicrosetosus Forel (Hymenoptera - Formicidae). Ciência e Agrotecnologia, v. 23, p. 208-211, 1999.

FERREIRA, F. A. Patologia florestal: principais doenças florestais no Brasil. Viçosa: Sociedade de Investigações Florestais, $1989.570 \mathrm{p}$.

FREITAS, S.; BERTI FILHO, E. Efeito do desfolhamento no crescimento de Eucalyptus grandis Hill Ex. Maiden (Myrtaceae). IPEF, Piracicaba, n. 47, p. 36-43, 1994.

KULMAN, H. M. Effects of insect defoliation on growth and mortality of trees. Annual Review of Entomology, v. 16, p. 289324, 1971.

LEWIS, T.; NORTON, G. A aerial baiting to control leaf-cutting ants (Formicidae: Atinni) in Trinidad. Bulletin of Entomological Research, v. 63, p. 289-303, 1973. 
MARTINEZ, G. S.; WAGNER, M. R. Sawfly (Hymenoptera: Diprionidae) and Artificial Defoliation Affects Above-and Blow-Grownd Growth of Ponderosa Pine Seedlings. Journal of Economic Entomology, v. 87, p. 1038-1045, 1994.

MENDES FILHO, J. M. A. Técnicas de combate à formiga. IPEF, n. 75, p. 1-19, 1979.

NICKELE, M. A. Distribuição espacial, danos e planos de amostragem de Acromyrmex crassispinus (Forel, 1909) (Hymenoptera: Formicidae: Myrmicinae) em plantios de Pinus taeda L. (Pinaceae). 2008, 111 p. Dissertação (Mestrado em Ciências Biológicas, Área de Concentração em Entomologia) Universidade Federal do Paraná, Curitiba.

REZENDE, J. P.; PEREIRA, A. R.; OLIVEIRA, A. D. Espaçamento ótimo para a produção de madeira. Revista Árvore, v. 7, p. 30-43, 1983.
RIBEIRO, G. T.; MENDONÇA, M. C. Controle de formigas cortadeiras. In: Seminário sobre silvicultura em florestas plantadas. 1., 2004, Vitória. Anais... Viçosa: SIF, p. 40-83, 2004.

RIBEIRO, G. T.; WOESSNER, R. A. Efeito de diferentes níveis de desfolha artificial, para avaliação de danos causados por saúvas (Atta spp.), em árvores de Gmelina arborea Linnée e de Pinus caribaea var. hondurensis Barr., Golf. Anais da Sociedade Entomológica do Brasil, v. 9, p. 261-272, 1980.

VILELA, E. F. Status of leaf-cutting ant control in forest plantation in Brazil. In: LOFGREEN, C.S. VAN DER MEER, R.K. (Eds.) Fire ants and leaf-cutting ants: biology and management. Bouder, Westview press. 1986, p. 399-408.

ZANUNCIO, J. C., LARANJEIRO, A. J.; SOUZA, O. Controle de Acromyrmex subterraneus Santschi (Hymenoptera: Formicidae) com sulfluramida. Anais da Sociedade Entomológica do Brasil, v. 25, p. 383-388, 1996.

Recebido em 16 de novembro de 2010 e aprovado em 22 de março de 2011 